\title{
Personnel reviewers 2016
}

Personnel reviewers 2016

List of reviewers from 1 January to 31 December 2016

Abdul Kohar, Umar Haiyat

Universiti Teknologi Malaysia, Malaysia

Accquaah, Moses

University of North Carolina Greensboro, USA

Açıkgöz, Atif

Fatih University, Turkey

Adikaram, Arosha

University of Colombo, Sri Lanka

Afiouni, Fida

American University of Beirut, Lebanon

Agarwal, Madhushree

Management Development Institute,

Gurgaon, India

Agarwal, Upasna A.

NITIE, India

Agarwala, Tanuja

University of Delhi, India

Ahmed, Masoom

Glyndwr University, United Kingdom of

Great Britain and Northern Ireland

Akyüz, Kadri Cemil

Karadeniz Technical University,

Turkey

Albadry, Omaima

Alegre, Joaquin

University of Valencia, Spain

Alghamdi, Ibrahim

Glasgow Caledonian University, United

Kingdom of Great Britain and Northern

Ireland

Alhejji, Hussain

University of Limerick, Ireland

Allen, Mathew

Manchester University, United Kingdom of

Great Britain and Northern Ireland

Alony, Irit

University of Wollongong, Australia

Altin Gumussoy, Cigdem

ITU, Turkey
Al-Waqfi, Mohammed

United Arab Emirates University,

United Arab Emirates

Andersen, Torben

University of Southern Denmark, Denmark

Anderson, Valerie

University of Portsmouth, United Kingdom

of Great Britain and Northern Ireland

Arevshatian, Lilith

Kingston University, United Kingdom of

Great Britain and Northern Ireland

Aristovnik, Aleksander

University of Ljubljana, Slovenia

Armstrong, Craig

University of Alabama, USA

Arndt, Aaron

Old Dominion University, USA

Arnold, John

Arora, Ridhi

LM Thapar School of Management,

Thapar University Patiala, India

Audenaert, Mieke

University Ghent, Belgium

Aydin, Erhan

Brunel University, United Kingdom of Great

Britain and Northern Ireland

Backhaus, Kristin

SUNY New Paltz, United Kingdom of Great

Britain and Northern Ireland

Bainbridge, Hugh

University of New South Wales,

Australia

Balabanova, Evgeniya

Higher School of Economics,

Russian Federation

Ballesteros, José

Universidad de Las Palmas de Gran

Canaria, Spain

Bambacas, Mary

UniSA, Australia

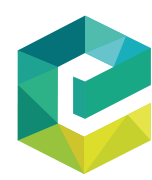

Personnel Review Vol. 46 No. 1, 2017 pp. $171-180$ hing Limited 
PR

46,1
Bande, Belén

Universidad de Navarra, Spain

Baron, Louis

ESG UQAM, Canada

Barrena-Martinez, Jesus

Universidad de Cádiz, Spain

Barron, Laura

US Air Force, USA

Barrow, Mark

University of Auckland, New Zealand

Barton, Harry

Nottingham Business School,

United Kingdom of Great Britain and

Northern Ireland

Bartram, Timothy

Baruch, Yehuda

Southampton Business School,

United Kingdom of Great Britain and

Northern Ireland

Basto-Pereira, Miguel

Universidade do Minho, Portugal

Bataille, Christine

Bawole, Justice

Beaver, Greg

University of Minnesota, USA

Bee, Mark

Southampton Solent University,

United Kingdom of Great Britain and

Northern Ireland

Belausteguigoitia, Imanol

Instituto Tecnológico Autónomo de México

(ITAM), Mexico

Bennett, Dawn

Curtin University, Australia

Berberoglu, Aysen

Cyprus International University, Cyprus

Berkley, Robyn

Southern Illinois University Edwardsville,

United Kingdom of Great Britain and

Northern Ireland

Bhanugopan, Ramudu

Charles Sturt University, Australia

Bhattacharya, Sonali

Symbiosis Centre for Management and

Human Resource Management (SCMHRD),

Symbiosis International University (SIU),

India

Bhatti, Muhammad

King Faisal University, Saudi Arabia

Biggane, Jonathan

California State University, Fresno, USA
Biilsma-Frankema, Katinka

Billing, Tejinder

Rowan University, USA

Birkenmeier, Betty

Texas A\&M University, USA

Bish, Adelle

Queensland University of Technology,

Australia

Blackman, Deboral

UNSW Canberra, Australia

Bluhm, Dustin

University of Colorado Colorado Springs,

USA

Bok, Stephen

University of Texas in Arlington, USA

Boyatsis, Richard

Case Western Reserve University, USA

Bozionelos, Nikos

Audencia, France

Braga, Beatriz

Fundacao Getulio Vargas Escola de

Administracao de Empresas de Sao Paulo,

Brazil

Brammer, Stephen

Brookes, Michael

Brooks, Sarah

Brown, Donna

Royal Holloway, University of London,

United Kingdom of Great Britain and

Northern Ireland

Brown, Travor

Memorial University of Newfoundland,

Canada

Brunetto, Yvonne

Southern Cross University, Australia

Buglear, John

Buick, Fiona

University of Canberra, Australia

Burke, Ronald

York U

Buttigieg, Sandra

University of Malta, Malta

Buyens, Dirk

University Ghent, Belgium

Cafferkey, Kenneth

Universiti Tun Abdul Razak, Malaysia

Cai, Zhenyao

Hong Kong Baptist University, Hong Kong

Callaghan, Chris

University of the Witwatersrand,

South Africa 
Callahan, Thomas

University of Michigan - Dearborn,

United Kingdom of Great Britain and

Northern Ireland

Cancino, Christian

University of Chile, Chile

Caniëls, Marjolein

Open University of the Netherlands,

The Netherlands

Carlisle, Yvonne

Nottingham Trent University, United Kingdom

of Great Britain and Northern Ireland

Carlos, Vera

University of Beira Interior, Portugal

Carmichael, Terri

Casson, Marguerite

Dalhousie University, Canada

Castanheira, Filipa

Novas School of Business and Economics,

Portugal

Catano, Vic

St. Mary's University, Canada

Cavanagh, Thomas

Dominican University of California, USA

Caven, Valerie

Nottingham Trent University,

United Kingdom of Great Britain and

Northern Ireland

Çelik, Gözde

Çukurova University, Turkey

Černe, Matej

University of Ljubljana, Faculty of

Economics, Slovenia

Cha, Yunsuk

Dong-A University, Republic of Korea

Chambel, Maria

University of Lisbon, Portugal

Chan, AWH

The University of Hong Kong, Hong Kong

Chan, Christopher

York University, Canada

Chan, Elisa

Ecole hoteliere de Lausanne, Switzerland

Chan, Paul

The University of Manchester,

United Kingdom of Great Britain and

Northern Ireland

Chandler, Nicholas

Budapesti Szamviteli Foskola Penzugyi es

Szamviteli Kar, Hungary
Chang, Jung-Nung

Ming Chuan University, Taiwan

Chang, Man-Ling

Asia University, Taiwan

Chaudhary, Richa

Indian Institute of Technology Patna,

India

Chaudhry, Naveed Iqbal

Anglia Ruskin University,

United Kingdom of Great Britain

and Northern Ireland

Chen, Tingting

Lingnan University, Hong Kong

Chen, Yu-Ping

Cheng, Cindy

La Trobe University, Australia

Cheng, Eddie W.L.

The Education University of Hong Kong,

Hong Kong

Cheng, Shih Yu (Cheryl)

National Cheng Kung University,

Tainan City 701, Taiwan

Chhinzner, Nita

University of Guelph, Canada

Chiang, Yun-Haw

Ming Chuan University, Taiwan

Chiu, Yung-Ho

Soochow University, Taiwan

Cho, Yonjoo

Choi, Byoung Kwon

Sangmyung University, Republic of Korea

Chong, Chin

Multimedia University, Malaysia

Chowhan, James

McMaster University, Canada

Clark, Mark

Clarke, Marilyn

University of Adelaide, Australia

Coffey, Jane

Curtin University, Australia

Cohen, Aaron

University of Haifa, Israel

Colakoglu, Saba

Berry College, USA

Conchado, Andrea

Universitat Politècnica de València, Spain

Connell, Julia

UTS, Australia

Cook, Christian

Mount Royal University, Canada
Personnel
reviewers 2016

173 
PR

46,1
Cooke, Gordon

Memorial University of Newfoundland,

Canada

Cooper, Brian

Monash University, Australia

Cordón Pozo, Eulogio

University of Granada, Spain

Correia, Daba

Culpin, Vicki

Ashridge, United Kingdom of Great Britain

and Northern Ireland

Cunningham, Li Xue

Cass Business School, United Kingdom of

Great Britain and Northern Ireland

Curran, Michael

Strayer University, USA

d'Armagnac, Sophie

Toulouse Business School, Université de

Toulouse, France

Dartey-Baah, Kwasi

University of Ghana Business School, Ghana

Davies, Gary

Davis, Ann

Aston University, United Kingdom of

Great Britain and Northern Ireland

Davis, Walter

University of Mississippi, USA

De Clercq, Dirk

Brock University, Canada

de Grip, Andries

de Sivatte, Isabel

IE University, Spain

Dedahanov, Alisher

Yeungnam, Republic of Korea

Dermol, Valerij

International School for Social and Business

Studies, Slovenia

Deschacht, Nick

KU Leuven, Belgium

Devece, Carlos

Universitat Politècnica de València, Spain

Devonish, Dwayne

The University of West Indies, Barbados

Dhar, Rajib

IIT Roorkee, India

Dick, Penny

University of Sheffield, United Kingdom of

Great Britain and Northern Ireland

Dimitrova, Mihaela

Oakland University, USA

Ditzel, Liz

Otago Polytechnic, New Zealand
Dixon, Pamela

Viterbo University, USA

Djebarni, Ramdane

South Wales University, United Kingdom of

Great Britain and Northern Ireland

Dominguez, Caroline

UTAD, Portugal

Donnelly, Rory

University of Birmingham,

United Kingdom of Great Britain

and Northern Ireland

Doughty, Dave

Nottingham Trent University,

United Kingdom of Great Britain and

Northern Ireland

Drew, Hilary

University of the West of England,

United Kingdom of Great Britain and

Northern Ireland

Dunlap, Patrick

United Kingdom of Great Britain and

Northern Ireland

Egan, Toby

University of Maryland at College Park,

USA

Ejumudo, Kelly

Delta State University, Abraka, Nigeria

Fan, Di

Curtin University, Australia

Farrell, Jennifer

University of Limerick Kemmy Business

School, Ireland

Fiksenbaum, Lisa

York University, Canada

Finegan, Joan

University of Western Ontario, Canada

Finney, Treena

University of South Alabama, USA

Fisher, Sandra

Clarkson University, USA

Flynn, Matt

Newcastle University, United Kingdom of

Great Britain and Northern Ireland

Foley, Dennis

University of Newcastle, Australia

Fontinha, Rita

University of Reading Henley Business

School, United Kingdom of Great Britain

and Northern Ireland

Foster, Bill

Dalhousie University, Canada 
Foster, Carley

Nottingham Trent University,

United Kingdom of Great Britain and

Northern Ireland

Francis, Helen

Edinburgh Napier University,

United Kingdom of Great Britain and

Northern Ireland

Freire, Carla

Economics and Management School,

University of Minho, Portugal

French, Erica

QUT, Australia

Fried, Andrea

Linköping University, Sweden

Froese, Fabian Jintae

$\mathrm{Fu}, \mathrm{Na}$

Dublin City University, Ireland

Fujimoto, Yuka

Sunway University, Malaysia

Galavan, Robert

National University of Ireland Maynooth,

Ireland

Gallego-Álvarez, Isabel

University of Salamanca, Spain

Garavan, Thomas

University of Limerick, United Kingdom of

Great Britain and Northern Ireland

Gatenby, Mark

Geare, Alan

University of Otago, New Zealand

Genin, Emilie

Universite de Montreal, Canada

George, Christeen

University of Hertfordshire,

United Kingdom of Great Britain and

Northern Ireland

Ghislieri, Chiara

University of Turin, Italy

Ghorbani, Majid

Renmin University of China, China

Gianecchini, Martina

University of Padova, Italy

Gibson, Jennifer

Fors Marsh Group LLC, USA

Gill, Carol

Melbourne Business School, Australia

Gillon, Anne Clare

Glaister, Alison

University of York, United Kingdom of

Great Britain and Northern Ireland
Gomes, Daniel

Personnel

College of Education - Polytechnic Institution reviewers 2016

of Coimbra, Portugal

Goñi Legaz, Salomé

Universidad Pública de Navarra, Spain

Gonzalez, Jorge

University of Texas - Rio Grande Valley, USA

Gordon, Judith

Boston College, USA

Gossett, Charles

Sacramento State, USA

Gotsis, George

National and Kapodistrian University of

Athens, Greece

Greener, Susan

University of Brighton, United Kingdom

of Great Britain and Northern Ireland

Grimani, Katerina

National and Kapodistrian University of

Athens, Greece

Grover, Steven

University of Otago, New Zealand

Guarnaccia, Cinzia

University of Palermo, Italy

Guerci, Marco

Politecnico di Milano, Italy

Guo, Steve

California State Polytechnic University

Pomona, USA

Haines, Victor

University of Montreal, Canada

Hällsten, Freddy

School of Business, Economics and Law,

Sweden

Hameed, Imran

University of Cental Punjab, Pakistan

Hamilton, Leah

Mount Royal University, Canada

Hammer, Leslie

Harley, Bill

U Melbourne, Australia

Harney, Brian

$D C U$, Ireland

Harrison, Jennifer

NEOMA, France

Hartman, Nathan

Illinois State University, USA

Harvey, Paul

University of New Hamshire, USA

Hashim, Junaidah

International Islamic University Malaysia,

Malaysia 
PR

46,1

176
Hechanova, Regina

Ateneo de Manila University, Philippines

Hennekam, Sophie

ESC La Rochelle School of Business, France

Henstra, Daniel

Herrbach, Olivier

Université de Bordeaux, France

Holm, Anna

Aarhus University, Business and Social

Sciences, Denmark

Holmvall, Camilla

Saint Mary's University, Canada

Hughes, Karen

University of Alberta, Canada

Hunter, Paul

University of Glasgow, United Kingdom of

Great Britain and Northern Ireland

Hutchinson, Susan

Univeristy of West of England,

United Kingdom of Great Britain and

Northern Ireland

Huzell, Henrietta

Karlstad University, Sweden

Imer, Pinar

Kadir Has University, Turkey

Inelmen, Kivanc

Bogazici Universiy, Turkey

Inglis, Loretta

Monash, Australia

Inyang, Benjamin James

University of Calabar, Nigeria

Jansen, Karen

Jansen, Paul

VU University Amsterdam, The Netherlands

Jeffrey, Scott

Monmouth University, USA

Jenkins, Jade

Nothern Illinois University, USA

Jiang, Chun-Yan

Nanjing University, China

Jiao, Changquan

Lakehead University, Canada

Jimenez-Jimenez, Daniel

University of Murcia, Spain

Joo, Baek-Kyoo

Georgia Southwestern State University, USA

Jyoti, Jeevan

University of Jammu, India

Kabat-Farr, Dana

Kailasapathy, Pavithra

Kamenou-Aigbekaen, Nicolina
Heriot Watt University, United Kingdom of

Great Britain and Northern Ireland

Khan, Muhammad Burdbar

University of Lincoln, United Kingdom of

Great Britain and Northern Ireland

Khaola, Peter

National University of Lesotho, Lesotho

Khoreva, Violetta

Hanken School of Economics, Finland

Kirk, Susan

Klarsfeld, Alain

Toulouse Business School, France

Knies, Eva

Utrecht University, The Netherlands

Köllen, Thomas

Wirtschaftsuniversitat Wien, Austria

Kopperud, Karoline

Kougiannou, Konstantina

Nottingham Trent University,

United Kingdom of Great Britain and

Northern Ireland

Krishnan, Venkat

Center for Oneness and Transforming

Leadership, India

Kulkarni, Mukta

Indian Institute of Management Bangalore,

India

Kunday, Özlem

Yeditepe Üniversity, Turkey

Kuron, Lisa

Wilfrid Laurier University, Canada

Kuvaas, Bård

BI Norwegian Business School, Norway

Kwesiga, Eileen

Bryant University, USA

Lam, Helen

Athabasca University, Canada

Lamond, David

Victoria University, Australia

Langhammer, Kristina

Stockholm University, Sweden

Lau, Dora

Chinese University of Hong Kong,

Hong Kong

Lauzier, Martin

Université du Québec en Outaouais, Canada

Lee, Amanda

Lee, Gregory

University of the Witwatersrand, South Africa

Lee, Junghyun

University of Michigan-Dearborn, USA 
Lee, Soo-Hoon

Old Dominion University, USA

Lengnick-Hall, Mark

University of Texas at San Antonio,

USA

Livanos, Ilias

Cedefop, Greece

Lopez-Cabrales, Alvaro

Universidad Pablo de Olavide, Spain

Luchman, Joseph

Fors Marsh Group LLC, USA

McCalman, David

University of Central Arkansas, USA

Mccarthy, Jean

University of Limerick, Ireland

McKeown, Tui

Monash University Faculty of Business and

Economics, Australia

McNally, Jeffrey

University of New Brunswick, Canada

McPhee, Deborah

Brock University, Canada

Maiolo, Elisa

University "G. d'Annunzio" of Chieti, Italy

Maley, Jane

Macquarie University, Australia

Mano, Rita

Uni. of Haifa, Israel

Manolchev, Constantine

University of Plymouth,

United Kingdom of Great Britain

and Northern Ireland

Marchand, Catherine

University of Kent, United Kingdom of

Great Britain and Northern Ireland

Martinez, Patricia G.

Loyola Marymount University, USA

Martinez-Fiestas, Myriam

ESAN University, Peru

Martins, Nico

University of South Africa,

South Africa

Martinson, Brian

Tarleton State University, USA

Mazánek, Lukáš

Vysoke uceni technicke v Brne Fakulta

podnikatelska, Czech Republic

Meneghel, Isabella

Universitat Jaume I, Spain

Messmann, Gerhard

University of Regensburg, Germany
Mharapara, Tagonei

The University of Auckland,

United Kingdom of Great Britain and

Northern Ireland

Milner, Julia

Xi'an Jiaotong-Liverpool University, China

Miraglia, Mariella

Norwich Business School, United Kingdom

Personnel
reviewers 2016

$+\frac{10}{20}$

Mistry, Sal

Southern Methodist University, USA

Mitchell, Ivan

Oxford Brookes University Business School,

United Kingdom of Great Britain and

Northern Ireland

Mohd Rasdi, Roziah

Universiti Putra Malaysia, Malaysia

Morgan, Paul

Buckinghamshire New University,

United Kingdom of Great Britain and

Northern Ireland

Morganson, Valerie

University of West Florida, USA

Morrell, Daniel

Muchiri, Michael

RMIT University, Australia

Mulder, Regina

University of Regensburg, Germany

Munir, Yasin

Universiti Tecknologi Malaysia, Malaysia

Nachmias, Stefanos

York St John University, United Kingdom of

Great Britain and Northern Ireland

Nankervis, Alan

Curtin University, Australia

$\mathrm{Ng}$, Daniel

The Hong Kong Polytechnic University,

Hong Kong

$\mathrm{Ng}$, Eddy

Dalhousie University, Canada

Ngunjiri, Faith

Concordia College, USA

Niu, Han-Jen

Tamkang University, Taiwan

Nkomo, Emmanuel

University of the Witwatersrand,

South Africa

Nolan, Connie

Norman, Thomas

California State University, Dominguez

Hills, USA 
PR

46,1

178
Notelaers, Guy

Nuñez, Imanol

Universidad Publica de Navarra, Spain

Nyathi, Nceku

University of Cape Town, South Africa

Olafsen, Anja

University College of Southeast Norway,

United Kingdom of Great Britain and

Northern Ireland

Olsson, Birgitta

Lund University, Sweden

Ortenblad, Anders

Nord University, Norway

Ozcelik, Hakan

California State University, Sacramento, USA

Ozturk, Mustafa

Palermo, Ofelia

Palmer, Adam

University of Winchester, United Kingdom

of Great Britain and Northern Ireland

Papageorgiou, Elmarie

University of the Witwatersrand, South

Africa

Parkinson, Ann

Henley Business School, United Kingdom of

Great Britain and Northern Ireland

Pasamar, Susana

University Pablo de Olavide, Spain

Passmore, Jonathan

Mondays Psychologists, United Kingdom of

Great Britain and Northern Ireland

Patton, Eric

Saint Joseph|s University Erivan K. Haub

School of Business, USA

Pedrini, Giulio

University of Bologna, Italy

Pérez-López, M. Carmen

University of Granada, Spain

Petty, Ryan

Roosevelt University, USA

Pieterse, Anne N.

Erasmus University Rotterdam,

The Netherlands

Pio, Edwina

Auckland University of Technology,

New Zealand

Podolsky, Mark

York University, Canada

Pointon, Julia

De Montfort University, United Kingdom of Great Britain and Northern Ireland
Poon, June

Universiti Kebangsaan Malaysia,

Malaysia

Porschitz, Emily

Keene State College, USA

Power, Jacqueline

Price, Deborah

de Montfort University, United Kingdom of

Great Britain and Northern Ireland

Psychogios, Alexandros

University of Hull, United Kingdom of

Great Britain and Northern Ireland

Quental, Camilla

Audencia Business School, France

Raiden, Ani

Rajendran, Diana

Ramalho, Nelson

ISCTE-Instituto Universitario de Lisboa,

Portugal

Ramos, Jose

University of Valencia, Spain

Ravenswood, Katherine

Rees, Gary

University of Portsmouth, United Kingdom

of Great Britain and Northern Ireland

Reimer, Marilee

St Thomas University, Canada

Resnick, Sheilagh

Nottingham Trent University,

United Kingdom of Great Britain and

Northern Ireland

Rice, John

University of New England, Australia

Rodrigues, Susana

Faculty of Psychology and Educational

Sciences, University of Porto, Portugal

Rodriguez, Jenny

Rodriguez-Garzon, Ignacio

UPC, Peru

Rodwell, John

Swinburne University of Technology,

Australia

Roper, Ian

Middlesex Unversity, United Kingdom of

Great Britain and Northern Ireland

Russ-Eft, Darlene

Oregon State University, USA

Ryan, James

Sammarra, Alessia

University of L'Aquila, Italy 
Samnani, Al-Karim

York University, Canada

Samuel, Micheal

University of the Witwatersrand,

South Africa

Sanchez Quiros, Isabel

Universdad Complutense de Madrid, Spain

Saridakis, George

Kingston University, United Kingdom of

Great Britain and Northern Ireland

Saxena, Stuti

National Innovation Foundation, India

Schlosser, Francine

University of Windsor, Canada

Scott-Ladd, Brenda

Edith Cowen University, Australia

Scrima, Fabrizio

Université de Rouen, France

Sears, Greg

Carleton University, Canada

Shaffakat, Samah

INSEAD Asia Campus, Singapore

Shantz, Amanda

University of Greenwich, United Kingdom

of Great Britain and Northern Ireland

Sharma, Jyoti

Indian Institute of Technology, India

Sharma, Jyoti

Shri Mata Vaishno Devi University, India

Shea, Catherine

Northwestern University, USA

Sheehan, Maura

NUI Galway, Ireland

Shen, Yan

Shi, Bing

London South Bank University,

United Kingdom of Great Britain and

Northern Ireland

Shipton, Helen

Nottingham Trent University,

United Kingdom of Great Britain and

Northern Ireland

Shriberg, Art

Xavier University, USA

Sim, Siew-Chen

The University of Nottingham Malaysia

Campus, Malaysia

Sinha, Tammi

University of Winchester, United Kingdom of Great Britain and Northern Ireland
Slåtten, Terje

Lillehammer University College, Norway

Song, Fei

Ryerson University, Canada

Sozen, Cenk

Baskent University, Turkey

Stone, Thomas

Oklahoma State, USA

$\mathrm{Su}$, Sophia

Macquarie University, Australia

Sun, Li Yun

Macau UST, Macao

Sundram, Veera

Uitm, Malaysia

Sverke, Magnus

Stockholm University, Sweden

Swailes, Stephen

University of Huddersfield, United Kingdom

of Great Britain and Northern Ireland

Syed, Jawad

University of Huddersfield, United Kingdom

of Great Britain and Northern Ireland

Teo, Stephen

RMIT University, Australia

Teoh, Kevin

Birkbeck University of London,

United Kingdom of Great Britain and

Northern Ireland

Thurloway, Lynn

University of Reading Henley Business

School-Greenlands Campus,

United Kingdom of Great Britain and

Northern Ireland

Tian, Amy Wei

Curtin University, Australia

Tordera, Nuria

Universitat de València, Spain

Townsend, Keith

Griffith University, Australia

Travaglione, Antonio

Curtin University, Australia

Tremblay, Diane-Gabrielle

Tyagi, Akansha

Indian Institute of Technology, India

Urbach, Tina

University of Potsdam, Germany

Valcea, Sorin

Cleveland State University, USA

Van Arensbergen, Pleun

Radboud University Nijmegen,

The Netherlands
Personnel reviewers 2016 
PR

46,1

180 van Harten, Jasmijn

Utrecht University, The Netherlands

Varma, Arup

Loyola University Chicago, USA

Vuuren, Tinka

Open Universiteit of the Netherlands,

The Netherlands

Wadhwa, Preeti

Cal Poly Pomona, USA

Wang, Gordon

George Brown College, Canada

Wang, Jing

York University, Canada

Wapshott, Robert

University of Sheffield, United Kingdom of

Great Britain and Northern Ireland

Weale, Victoria

La Trobe Unversity, Australia

Wheatley, Daniel

University of Birmingham,

United Kingdom of Great Britain

and Northern Ireland

Wheeler, Tony

University of Rhode Island, USA

Wiblen, Sharna

University of Sydney, Australia

Williams van Rooij, Shahron

George Mason University, USA
Williamson, Mervywn

University of KwaZulu-Natal, South Africa

Winefield, Anthony

The University of South Australia, Australia

Wooten, Jadrian

The Pennsylvania State University,

United Kingdom of Great Britain and

Northern Ireland

$\mathrm{Wu}$, Ning

Nottingham Trent University,

United Kingdom of Great Britain and

Northern Ireland

Yang, Yi-Feng

Shu-Te University, Taiwan

$\mathrm{Yu}$, Andrew

Michigan State University, USA

Zhang, Haiyan

IBM, USA

Zhang, Michael

Zhang, Xiaozheng

Nottingham Trent University,

United Kingdom of Great Britain and

Northern Ireland

Zhao, Natalie Bin

Zheng, Connie

Deakin University, Australia

Zhu, Ying

University of South Australia, Australia 